\title{
Glass formation region and electrical conductivity in the system $\mathrm{B}_{2} \mathrm{O}_{3}-\mathrm{Li}_{2} \mathrm{O}-\mathrm{Li}_{3} \mathrm{PO}_{4}$
}

\author{
B BASU, H S MAITI and A PAUL \\ Materials Science Centre, Indian Institute of Technology, Kharagpur 721302 , India. \\ MS received 14 May 1982

\begin{abstract}
Glass formation region was determined for the $\mathrm{B}_{2} \mathrm{O}_{3}-\mathrm{Li}_{2} \mathrm{O}-\mathrm{Li}_{3} \mathrm{PO}_{4}$ system. Under the present experimental conditions, binary lithium borate glasses could be formed containing a maximum of $27 \mathrm{~mol} \% \mathrm{Li}_{2} \mathrm{O}$. However, this could be increased to $36 \mathrm{~mol} \%$ in the ternary system. Electrical conductivity was measured at temperatures ranging from room temperature to $350^{\circ} \mathrm{C}$. The temperature dependence of the electrical conductivity of these glasses follows Arrhenius equation. The conductivity increased with increasing alkali content. Maximum conductivity of the order of $10^{-4} \mathrm{ohm}^{-1} \mathrm{~cm}^{-1}$ was obtained with the glass containing about $36 \mathrm{~mol} \%$ $\mathrm{Li}_{2} \mathrm{O}$ at $250^{\circ} \mathrm{C}$. Activation energy for conduction also varied with total $\mathrm{Li}_{2} \mathrm{O}$ content.
\end{abstract}

Keywords. Glass formation region; electrical conductivity; lithium borate glasses; Arrhenius equation.

\section{Introduction}

Solid lithium ion conductors are increasingly used as electrolytes for high density miniature batteries. Most of the materials so far developed for this purpose are either single crystals or poly-crystalline in nature. Recently, some glassy lithium ion conductors have also been studied with conductivity comparable to that of their crystalline counterparts. Smedly and Angel (1978); Boehm and Angel (1979) reported a number of glasses in the system $\mathrm{Li}_{2} \mathrm{O}-\mathrm{LiF}-\mathrm{Li}_{2} \mathrm{SO}_{3}-\mathrm{Li}_{2} \mathrm{SO}_{4}-\mathrm{B}_{2} \mathrm{O}_{3}$ with total $\mathrm{Li}_{n} \mathrm{X}$ (where $\mathrm{X}=\mathrm{O}, \mathrm{F}$, $\mathrm{SO}_{4}, \mathrm{SO}_{3}$ ) content ranging from 43 to $84 \mathrm{~mol} \%$. A maximum conductivity of $2.26 \times 10^{-3}$ $\mathrm{ohm}^{-1} \mathrm{~cm}^{-1}$ was obtained at $200^{\circ} \mathrm{C}$ for the glass containing about $70 \mathrm{~mol} \% \mathrm{Li}_{n} \mathrm{X}$. Takahashi and Yamamoto (1979) studied glasses in the system $\mathrm{Li}_{2} \mathrm{O}-\mathrm{LiCl}-\mathrm{Al}_{2} \mathrm{O}_{3}-\mathrm{B}_{2} \mathrm{O}_{3}$ and obtained a maximum conductivity of $7 \times 10^{-3} \mathrm{ohm}^{-1} \mathrm{~cm}^{-1}$ at $300^{\circ} \mathrm{C}$. High lithium ion conduction has also been observed in the glass system $\mathrm{Al}\left(\mathrm{PO}_{3}\right)_{3}-\mathrm{LiF}-\mathrm{Li}_{2} \mathrm{O}$ (Evstrop'ev et al 1974; Jagla and Israd 1980). Glasses could be made in this system containing upto $80 \mathrm{~mol} \% \mathrm{LiF}+\mathrm{Li}_{2} \mathrm{O}$. A more detailed investigation on the system has been recently carried out (Kulkarni et al 1981). Malugani et al (1978) studied glasses in the system $\mathrm{LiPO}_{3}-\mathrm{Li}_{2} \mathrm{SO}_{4}$ and room temperature conductivity of the order of $10^{-7} \mathrm{ohm}^{-1} \mathrm{~cm}^{-1}$ has been reported. Systematic studies are being intensively pursued in various glass systems so as to increase the conductivity as much as possible. In this paper, the results obtained from the system $\mathrm{Li}_{2} \mathrm{O} \cdot \mathrm{B}_{2} \mathrm{O}_{3}-\mathrm{Li}_{3} \mathrm{PO}_{4}$ are reported.

\section{Experimental}

The raw materials used for glass preparation were of Analar grade $\mathrm{H}_{3} \mathrm{BO}_{3}$ and $\mathrm{Li}_{2} \mathrm{CO}_{3}$. $\mathrm{Li}_{3} \mathrm{PO}_{4}$ used was prepared in the laboratory. 


\subsection{Preparation of $\mathrm{Li}_{3} \mathrm{PO}_{4}$}

Lithium ortho-phosphate was prepared in the laboratory by. solid state reaction between $\mathrm{Li}_{2} \mathrm{CO}_{3}$ and $\left(\mathrm{NH}_{4}\right)_{2} \mathrm{HPO}_{4}$ at $800^{\circ} \mathrm{C}$. Stoichiometric amounts of $\mathrm{Li}_{2} \mathrm{CO}_{3}$ and $\left(\mathrm{NH}_{4}\right)_{2} \mathrm{HPO}_{4}$ were mixed in acetone as a slurry, dried overnight in an air-oven at $110^{\circ} \mathrm{C}$, heated slowly in an alumina crucible to drive out $\mathrm{CO}_{2}$, combined with water and ammonia, finally brought to $800^{\circ} \mathrm{C}$, and kept for $2 \mathrm{hr}$. The mixture was cooled, ground and the procedure repeated to ensure thorough mixing and complete chemical reaction: X-ray powder diffraction spectrum, using $\mathrm{Cu}-\mathrm{K}_{\alpha}$ radiation was taken to confirm the presence of the desired phase only.

\subsection{Glass melting}

Appropriate amounts of dry reagents $\left(\mathrm{H}_{3} \mathrm{BO}_{3}, \mathrm{Li}_{2} \mathrm{CO}_{3}\right.$, and $\left.\mathrm{Li}_{3} \mathrm{PO}_{4}\right)$ were mixed and melted in a platinum crucible at $950^{\circ} \mathrm{C}$, for about $30 \mathrm{~min}$ till a clear bubble-free liquid was formed. The resultant melts were poured on to a brass mould and subsequently annealed at $450^{\circ} \mathrm{C}$. The compositions of the different glasses melted are shown in figure 1. X-ray powder diffraction was used to check the formation of any crystalline phase.

\subsection{Electrical conductivity}

For measurement of conductivity, specimens were prepared in the form of rectangular tablets (approximately $10 \times 5 \times 2 \mathrm{~mm}$ ) or circular discs (radius $5 \mathrm{~mm}$ thickness 2 $\mathrm{mm}$ both approximately).

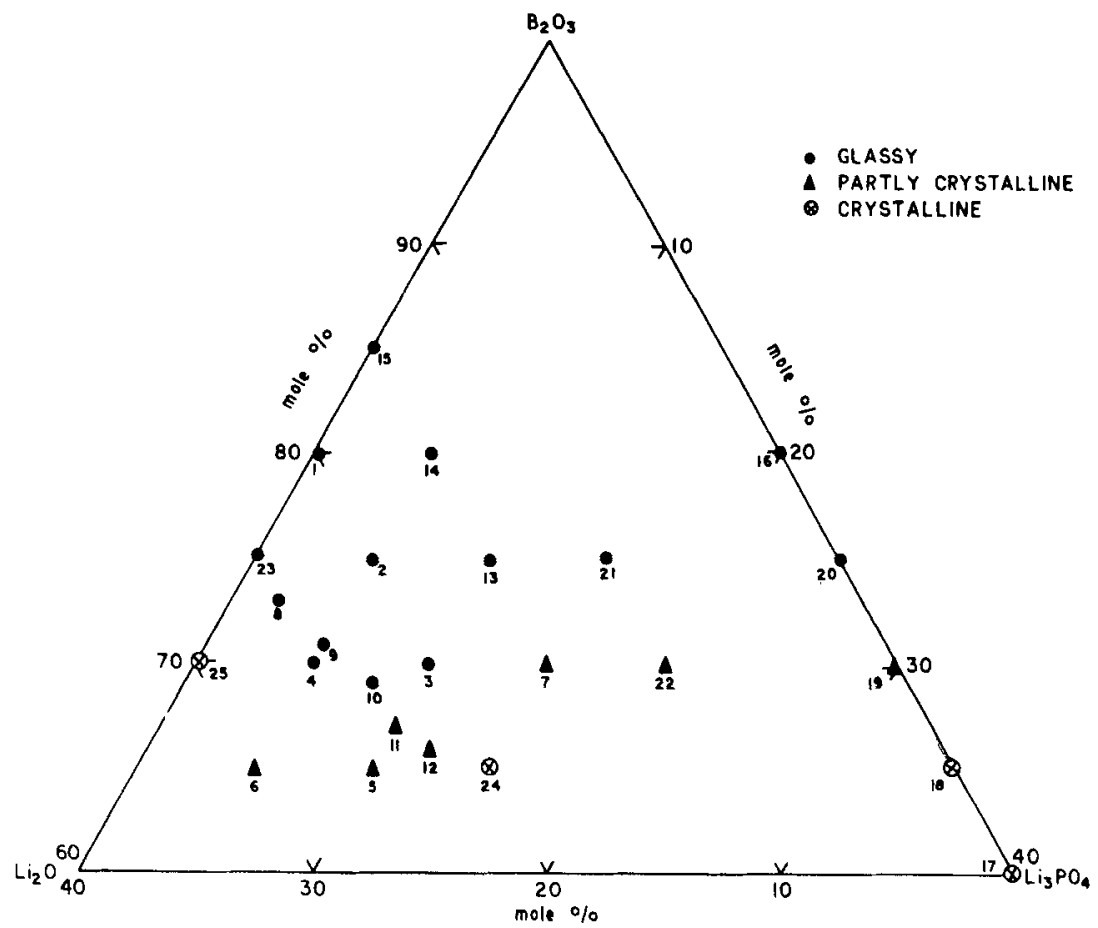

Figure 1. Glass formation region for the system $\mathrm{B}_{2} \mathrm{O}_{3}-\mathrm{Li}_{2} \mathrm{O}-\mathrm{Li}_{3} \mathrm{PO}_{4}$. 
For glasses in which very small portions of crystallized inclusion (figure 1, solid triangle) was observed, only the transparent glassy part was used for conductivity measurements. The polished surfaces of each sample were coated with silver paste and platinum foil electrodes were placed on either sides of the sample. The whole arrangement along with a thermocouple was assembled in a quartz tube which was maintained at a pressure of the order of $10^{-2} \mathrm{~mm}$ of $\mathrm{Hg}$. The temperature was controlled to within $\pm 1^{\circ} \mathrm{C}$, by a temperature controller over the range $30-350^{\circ} \mathrm{C}$. AC electrical conductivities were measured using a standard AC bridge (Wayne Kerr, model B224) at a frequency of $1592 \mathrm{~Hz}$ (the internal frequency of the bridge).

\section{Results and Discussion}

\subsection{Glass formation region}

Ten grams of the glass were melted at a time. The melt was cast in a brass mould and allowed to cool freely in air till, it was rigid enough to be transferred to the annealing furnace. Glass formation region under such experimental conditions in the $\mathrm{Li}_{2} \mathrm{O}-\mathrm{B}_{2} \mathrm{O}_{3}-\mathrm{Li}_{3} \mathrm{PO}_{4}$ system is shown in figure 1 . Table 1 gives the chemical composition, density and other data for these glasses.

In the calculation of the total $\mathrm{Li}_{2} \mathrm{O}$ content, both the lithia added as $\mathrm{Li}_{2} \mathrm{CO}_{3}$ and that present in $\mathrm{Li}_{3} \mathrm{PO}_{4}$ was taken into account. It may be seen from table 1 and figure 1 that under the present experimental conditions, glasses could be made with a maximum of about $36 \mathrm{~mol} \%$ of the total $\mathrm{Li}_{2} \mathrm{O}$ content.Concentration of lithium ion per unit volume was calculated from the chemical composition and density of these glasses. Figure 2 shows a plot of concentration of lithium ion against total $\mathrm{Li}_{2} \mathrm{O}$ content of the glasses. Despite extra complexity in structure caused by the addition of $\mathrm{Li}_{3} \mathrm{PO}_{4}$ to $\mathrm{Li}_{2} \mathrm{O}-\mathrm{B}_{2} \mathrm{O}_{3}$

Table 1. Composition, total $\mathrm{Li}_{2} \mathrm{O}$ content, density and $\mathrm{Li}$-ion concentration of the Glasses studied in the system $\mathrm{B}_{2} \mathrm{O}_{3}-\mathrm{Li}_{2} \mathrm{O}-\mathrm{Li}_{3} \mathrm{PO}_{4}$.

\begin{tabular}{ccccccc}
$\begin{array}{c}\text { Glass } \\
\text { No. }\end{array}$ & \multicolumn{2}{c}{ Composition $(\mathrm{mol} \%)$} & $\begin{array}{c}\text { Total } \mathrm{Li}_{2} \mathrm{O} \\
\text { content } \\
(\mathrm{mol} \%)\end{array}$ & $\begin{array}{c}\text { Density } \\
\left(\mathrm{cm}^{-3}\right)\end{array}$ & $\begin{array}{c}\text { Li-ion } \\
\text { concentration } \\
\left(\times 10^{22}\right)\left(\mathrm{cm}^{-3}\right)\end{array}$ \\
\hline 1 & 80 & 20 & 0 & 20.0 & 2.116 & 0.845 \\
2 & 75 & 20 & 5 & 26.19 & 2.170 & 1.12 \\
3 & 70 & 20 & 10 & 31.82 & 2.231 & 1.55 \\
4 & 70 & 25 & 5 & 30.95 & 2.243 & 1.42 \\
$;$ & 65 & 25 & 10 & 36.36 & 2.273 & 1.70 \\
5 & 55 & 30 & 5 & 35.70 & 2.294 & 1.73 \\
3 & 73 & 25 & 2 & 27.45 & 2.199 & 1.22 \\
10 & 59 & 23 & 8 & 32.41 & 2.256 & 1.48 \\
12 & 06 & 22 & 12 & 35.71 & 2.268 & 1.65 \\
14 & 80 & 15 & 5 & 21.43 & 2.146 & 0.88 \\
10 & 30 & 0 & 20 & 25.0 & 2.148 & 0.98
\end{tabular}




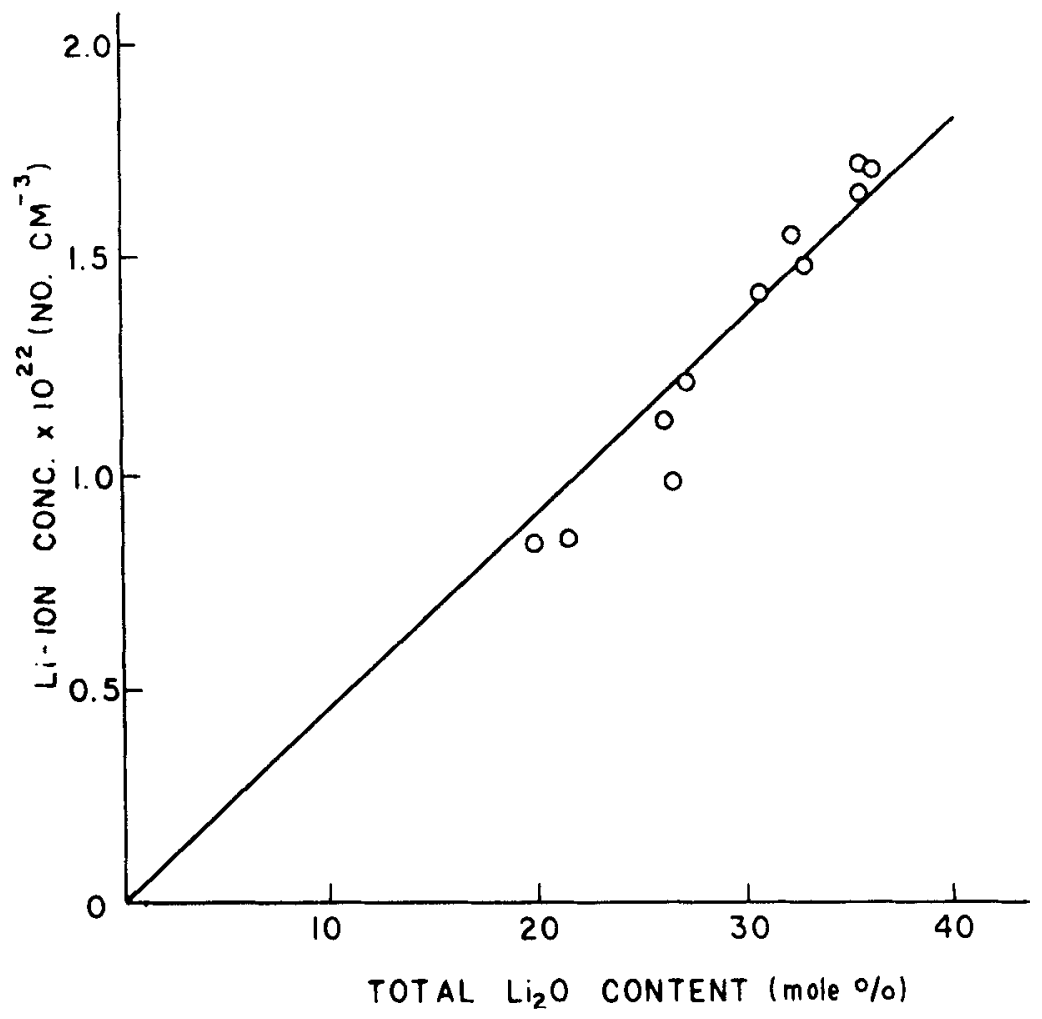

Figure 2. Variation of $\mathrm{Li}$-ion concentration with total $\mathrm{Li}_{2} \mathrm{O}$ content.

glasses, the volume concentration of lithium ion increases almost linearly with total $\mathrm{Li}_{2} \mathrm{O}$ content of these glasses. Figure 3 shows a plot of the molar volume of the glasses 23 , $8,9,10,11$ and 12 against $\mathrm{mol} \%$ of $\mathrm{Li}_{3} \mathrm{PO}_{4}$ present in them. All these six glasses are on the pseudo-binary line joining the two end components $\left(\mathrm{Li}_{2} \mathrm{O}, 3 \mathrm{~B}_{2} \mathrm{O}_{3}\right)$ and $\mathrm{Li}_{3} \mathrm{PO}_{4}$. It is interesting to note that the plot is linear and thus partial molar volumes of $\left(\mathrm{Li}_{2} \mathrm{O}\right.$, $3 \mathrm{~B}_{2} \mathrm{O}_{3}$ ) and $\mathrm{Li}_{3} \mathrm{PO}_{4}$ in mixtures within the composition range studied, do not change.

Under the experimental conditions of the present investigations, binary lithium borate melts containing more than $27 \mathrm{~mol} \% \mathrm{Li}_{2} \mathrm{O}$ devitrified very quickly during casting. However, under the same experimental conditions, the limit of glass formation could be extended to around $36 \mathrm{~mol} \% \mathrm{Li}_{2} \mathrm{O}$ (total) in the $\mathrm{Li}_{2} \mathrm{O}-\mathrm{B}_{2} \mathrm{O}_{3}-\mathrm{Li}_{3} \mathrm{PO}_{4}$ system with a consequent increase in the lithium ion concentration per unit volume.

\subsection{Temperature dependence of conductivity}

Electrical conductivity of all the glasses was measured in the temperature range $30-350^{\circ} \mathrm{C}$. The conductivity $\sigma$ followed the Arrhenius relation :

$$
\sigma=A_{0} \exp \left(-E_{c} / k T\right)
$$

where $T$ is the absolute temperature, $A_{0}$ is a constant, $k$ is the Boltzmann constant and $E_{c}$ is the activation energy for conduction. Some typical plots of $\log \sigma$ against $T^{\boldsymbol{L}_{1}}$ are shown in figure 4 . Activation energy for conduction $E_{c}$ for various glasses was calculated from 


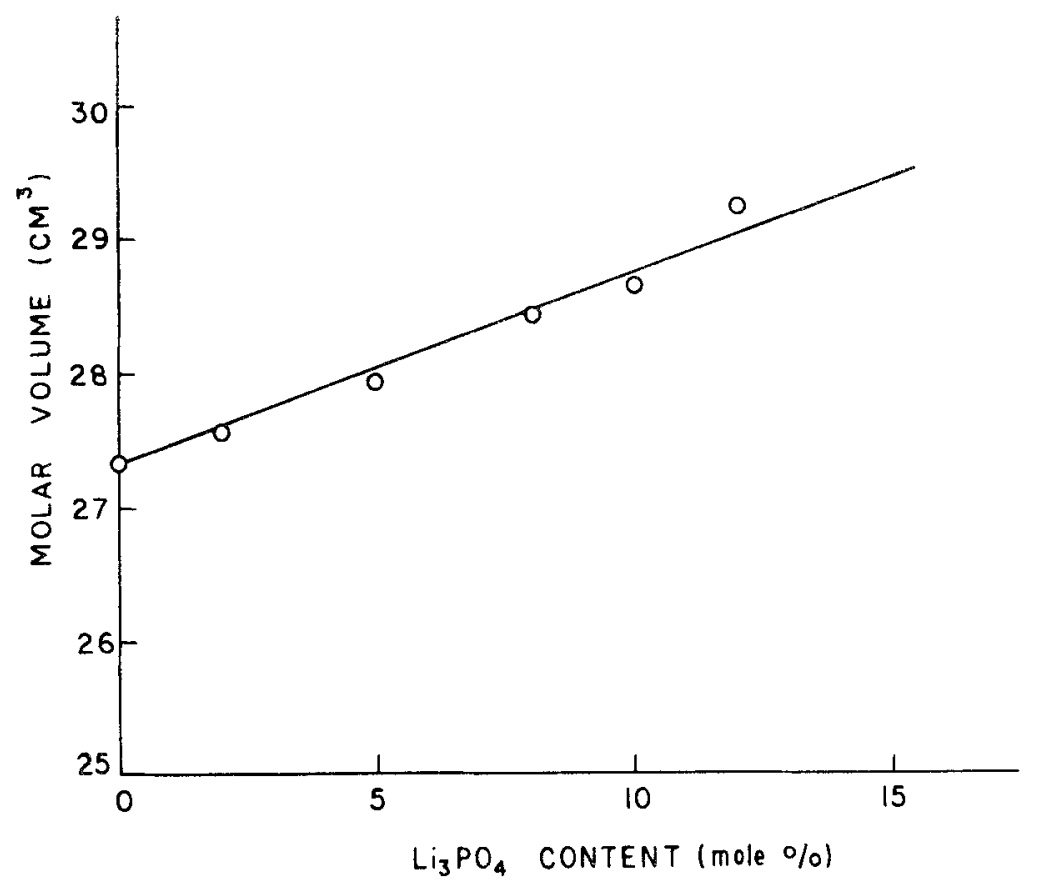

Figure 3. Variation of molar volume with $\mathrm{Li}_{3} \mathrm{PO}_{4}$ content.

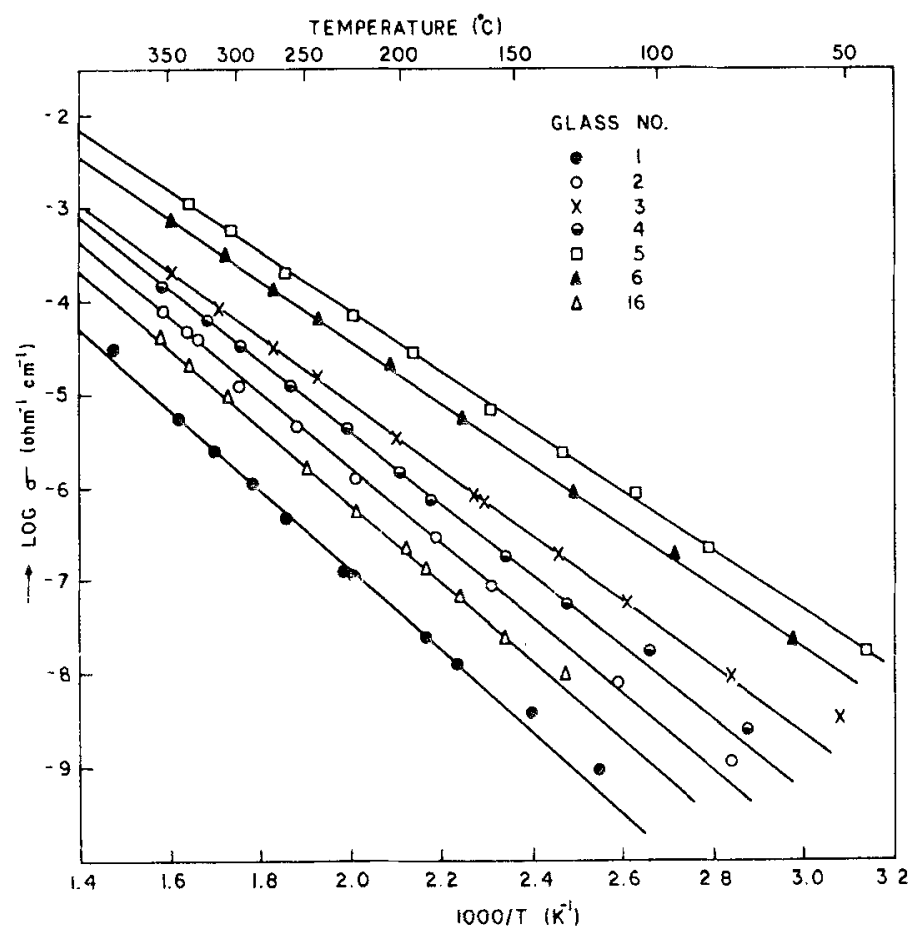

Figure 4. Typical plots showing temperature dependence of conductivity in the $\mathrm{B}_{2} \mathrm{O}_{3}-\mathrm{Li}_{2} \mathrm{O}-\mathrm{Li}_{3} \mathrm{PO}_{4}$ glasses. 


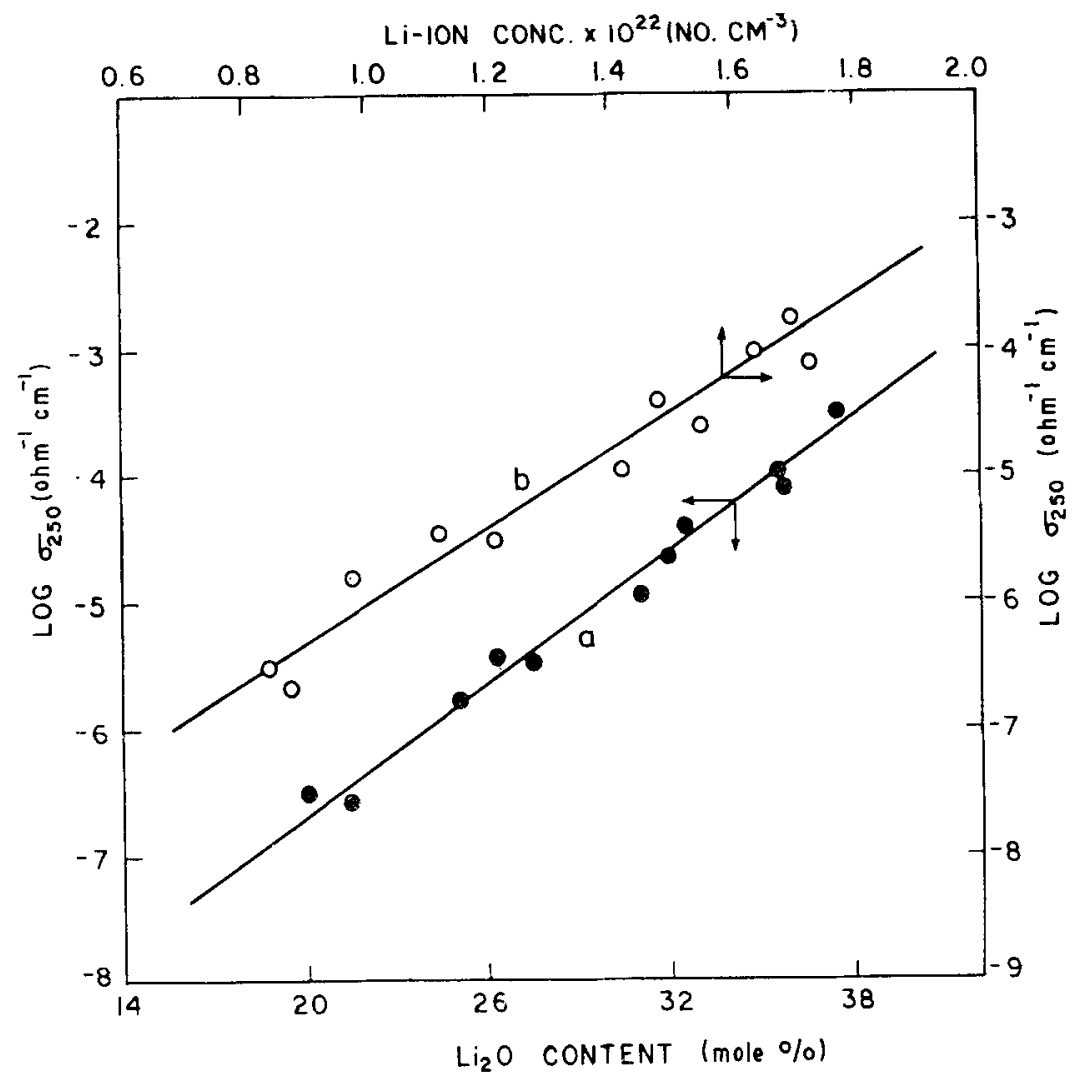

Figure 5. Variation of conductivitv at $250^{\circ} \mathrm{C}$ with (a) total $\mathrm{Li}_{2} \mathrm{O}$ content and (b) Li-ion concentration for the $\mathrm{B}_{2} \mathrm{O}_{3}-\mathrm{Li}_{2} \mathrm{O}-\mathrm{Li}_{3} \mathrm{PO}_{4}$ system.

the slope of such linear plots. Figure 5(a) shows the variation of conductivity at $250^{\circ} \mathrm{C}$, with total $\mathrm{Li}_{2} \mathrm{O}$ content of those glasses where a satisfactory linear relationship may be observed. A similar linear relationship exists between $\log \sigma_{250}$ and lithium ion concentration per unit volume of these glasses as shown in figure 5(b). The maximum conductivity obtained in this system is in the glass containing largest $\mathrm{Li}_{2} \mathrm{O}$ (total) content, i.e. $36.36 \mathrm{~mol} \% \mathrm{Li}_{2} \mathrm{O}$ having conductivity of the order of $10^{-4} \mathrm{ohm}^{-1} \mathrm{~cm}^{-1}$ at $250^{\circ} \mathrm{C}$.

The variation of activation energy with total $\mathrm{Li}_{2} \mathrm{O}$ content of these glasses is shown in figure 6. As in many other alkali containing binary oxide glasses (Otto 1966; Owen 1963), the activation energy decreases with incresing $\mathrm{Li}_{2} \mathrm{O}$ (total) content of these glasses.

In binary $\mathrm{Li}_{2} \mathrm{O}-\mathrm{B}_{2} \mathrm{O}_{3}$ glasses, addition of $\mathrm{Li}_{2} \mathrm{O}$ predominantly changes the oxygen coordination of boron from 3 to 4 up to about $40 \mathrm{~mol} \% \mathrm{Li}_{2} \mathrm{O}$ (Bray and O'Keefe 1963) breaks $\mathrm{P}-\mathrm{O}-\mathrm{P}$ bond with the formation of so-called non-bridging oxygen (Westman and Gartaganis 1957) $\mathrm{P}-\mathrm{O}^{-} \mathrm{Li}^{+}$. $\mathrm{Li}_{3} \mathrm{PO}_{4}$ contains $75 \mathrm{~mol} \% \mathrm{Li}_{2} \mathrm{O}$ and $25 \mathrm{~mol} \% \mathrm{P}_{2} \mathrm{O}_{5}$ whereas the highest $\mathrm{Li}_{2} \mathrm{O}$ content in binary lithium borate glass used in the present investigation contained only $25 \mathrm{~mol} \% \mathrm{Li}_{2} \mathrm{O}$. Although standard-free energy of formation of $\left(3 \mathrm{Li}_{2} \mathrm{O}\right.$, $\left.\mathrm{P}_{2} \mathrm{O}_{5}\right)$ is much more negative (stable) than that of $\left(\mathrm{Li}_{2} \mathrm{O}, 3 \mathrm{~B}_{2} \mathrm{O}_{3}\right)(\mathrm{Jeffes} 1975)$ in mixtures, 


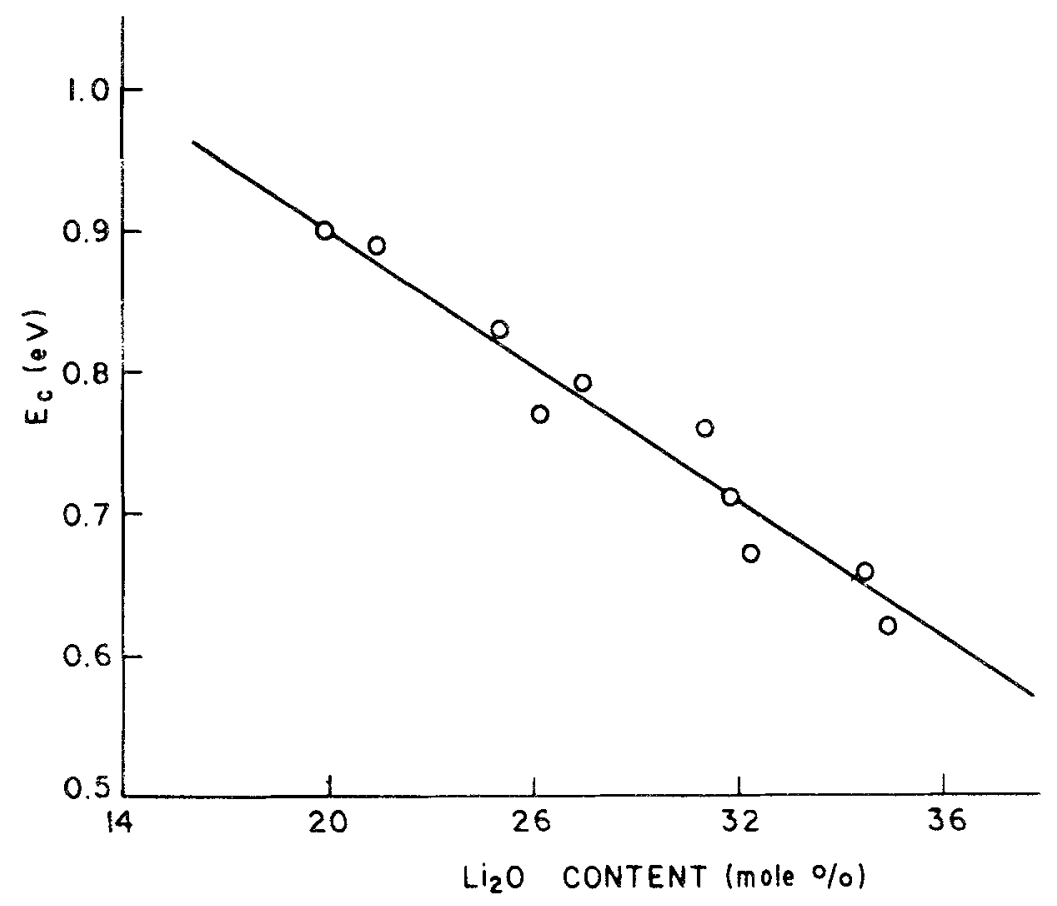

Figure 6. Variation of the activation energy for conduction $\left(E_{c}\right)$ with total $\mathrm{Li}_{2} \mathrm{O}$ content in $\mathrm{B}_{2} \mathrm{O}_{3}-\mathrm{Li}_{2} \mathrm{O}-\mathrm{Li}_{3} \mathrm{PO}_{4}$ glasses.

transfer of $\mathrm{Li}_{2} \mathrm{O}$ from phosphate matrix to borate matrix is still theoretically possible provided the chemical potential of lithium oxide is lowered by that process. Unfortunately, data for free energy of mixing in this system are not available and no definite suggestions can be made. However, the constancy of partial molar volume (this can be estimated from figure 3 by drawing tangents at individual compositions) does not indicate any such $\mathrm{Li}_{2} \mathrm{O}$ transfer.

Formation of borophosphate group with cristobalite type of structure in mixtures of borate and phosphate particularly containing low alkali oxide concentration is well known. Such borophosphate group formation involves co-ordination change of boron and $\pi$ bonding of phosphate group and is thus expected to alter the molar volume. As discussed before, no such significant change of molar volume was observed in the present system probably indicating absence of borosphate group in these glasses.

From all these evidences, it appears that $\left(\mathrm{Li}_{2} \mathrm{O}+\mathrm{B}_{2} \mathrm{O}_{3}\right)$ and $\mathrm{Li}_{3} \mathrm{PO}_{4}$ mixes almost ideally without any major structural change. However, by mixing $\mathrm{Li}_{3} \mathrm{PO}_{4}$ with lithium borate, glasses can be made with substantially larger concentration of $\mathrm{Li}^{+}$per unit volume and a consequent increase of lithium ion conductivity.

\section{Acknowledgement}

The authors thankfully acknowledge the partial financial assistance provided by the Council of Scientific and Industrial Research, New Delhi. 


\section{References}

Boehm L and Angel C A 1979 Fast ion transport in solids. (Eds) P Vashishta, J N Mundy and G K Shenoy (North Holland) 719

Bray P J and O'Keefe J G 1963 Phys. Chom. Glasses. 437

Evstrop'ev K K, Veksler G I and Kondrat'eva B S 1974 Dokl. Akad. Nauk. SSSR. 215902

Jagla M and Israd J O 1980 Mater. Res. Bull 151327

Jeffes J H E 1975 Silicate Ind. 12325

Kulkarni A R, Maiti H S and Paul A 1981 Glass formation and electrical conductivity in the system $L i F-L i_{2} O-A L\left(P O_{3}\right)_{3}$ Paper presented in the 45th Annual Session of Indian Ceramic Society.

Malugani J P, Wasniewski A, Doreau M and Robert G 1978 C R Acad. Sci. Paris, C287 455

Otto K 1966 Phys. Chem. Glasses 729

Owen A E 1963 Progr. Cer. Sci. 378

Smedly S I and Angel C A 1978 Solid State Commun. 2721

Takahashi T and Yamamoto Y 1979 Chem. Lett. 135136

Westman A E R and Gartaganis P A 1957 J. Am. Chem. Soc. 40293 